\title{
Ecological valuation in a transportation project: value transfer and spatial decision support systems
}

\author{
H. Y. Kim
}

Received: 22 November 2013/Revised: 1 April 2014/Accepted: 10 May 2014/Published online: 27 May 2014

(C) Islamic Azad University (IAU) 2014

\begin{abstract}
The main purpose is to identify the possibility of calculating ecological impact as an opportunity cost to estimate total costs of each alternative and to test the feasibility of the high-speed rail routes designed with different variables. If ecological impact can be accounted for as economic costs are, would it be safe to say a route with the shortest physical (Euclidian) distance is the most economically viable option? If the difference in construction and operation costs, the two most commonly used cost elements in conventional feasibility studies, is compensated by ecological benefits, is it reasonable choose a route that is environmentally beneficial, albeit slightly more circuitous than the shortest route? These are the main questions of this study, and the author answers using the spatial decision support system and ecosystem valuation approaches. The results imply that the saved ecological benefits may compensate for the induced losses in the long run, and thus, choosing a route with more ecological benefits could become a viable solution.
\end{abstract}

Keywords Ecological valuation - Transportation externalities · Texas Urban Triangle - Spatial decision support system · High-speed rail · Total cost analysis

\section{Introduction}

There have been a wide range of efforts to estimate environmental costs as a part of transport externalities.

\section{H. Y. Kim $(\bowtie)$}

Department of Landscape Architecture and Urban Planning,

Texas A\&M University, 3137 TAMU, College Station, TX

77843, USA

e-mail: hykim@arch.tamu.edu
Beginning in the early 2000s, researchers started focusing on environmental costs in transportation projects (Lee 2000; Adamowicz 2003; Janic 2003; Lu and Morrell 2006; Belhaj and Fridell 2010), and many studies have concentrated on accident, congestion, noise, and air pollution aspects (Abbaspour and Soltaninejad 2004; Banerjee et al. 2009; Mishra et al. 2010). Although some countries use monetary values when calculating the worth of particular environmental features consumed by a transportation project, the USA measure environmental resources in a separate study via a points system, not necessarily as features of financial significance (Hayashi and Morisugi 2000). Lee (2000) asserts that in US practices, considerations of environmental costs are often left out. There are mandatory procedures for some fixed costs, such as loss of habitat and wetlands, because federal law imposes the constraint of no net loss (Lee 2000). However, such fixed replacements often supply a limited perspective on ecological variations, and most estimates are made using an aggregate analysis without considering the spatial variation of each project.

Accordingly, the need for more specific assessments of the damages incurred to environmental features has prompted an academic interdisciplinary collaboration involving transportation planning, land management, and ecological economics. For example, two researchers calculated the marginal environmental costs of transportation systems at three different scales: local, regional, and global (Vossiniotis and Assimacopoulos 1999). Their findings suggest that the resulting environmental damages depend heavily on the technology used and the location of the transport activities. The application revealed a great variation of the environmental costs of transport depending on the transport mode, the emission control technology used, and the location of the transport task. In other words, transport externalities are site-specific and depend upon the 
nature of the project (Maxwell 1994; Lu and Morrell 2006; Wang and Sanders 2011). Therefore, should externalities be estimated on a case-by-case basis, the inclusion of context-specific measures would very likely have an impact on the final investment decision. The need for more location-specific measures is also found in other studies. Quinet (2003) wrote on techniques and approaches needed for environmental impact assessments. Location-specific measures are necessary when addressing the concerns of geographic aggregations, specifically when transportation impact cumulates from a small to larger scale. In cases where data availability is lacking, however, this becomes a hard task. Therefore, top-down or aggregation approaches are often used to assess the impact. The problem with using a macro-level analysis is that aggregated measures make it hard to distinguish the degree of precision between particular local circumstances and the types of transportation used to gauge the impact (Thompson 1993; Adamowicz 2003; Quinet 2003).

Therefore, to the extent of the environmental externalities, two things should be noticed. First, environmental impact and ecological consumption need to be distinguished. In previous studies, environmental externalities tend to represent the damages occurred to ecological features. As a result, detailed ecological consumption by a transport is often left out or considered a less dominant feature in the final decision. Environment as a whole, frequently measured at aggregate regional levels, contributes significantly to overall sustainability. However, if transport externalities are particularly site-specific and depend heavily on the nature of the project (Bockstael et al. 1995; Vossiniotis and Assimacopoulos 1999; Wilson et al. 2004; Turner et al. 2010), the way they are currently assessed requires a substantial amount of detail to elaborate on the changes made to ecological systems, not simply to the environment as a whole.

Second, as technology progresses to the point where location-specific estimates are available, the above-mentioned shortcoming can be resolved to a certain degree. Implementation of geographic information systems (GIS) or utilization of satellite images enables researchers to pinpoint the ecological changes induced by man-made structures. This is substantially different from what general externality studies have adopted to measure the environmental impact. Assessing accidents, congestion, noise, and air pollution as an opportunity cost provides a broader view in terms of externalities, and these have been measured without specific spatial variations. However, capturing the ecological features directly affected by a transportation decision requires details of geographic information, which should be taken into account at the beginning of the planning stage. Within those two regards, impact on ecological systems and environmental externalities as a whole should distinguish to a certain degree.

This study intends to articulate the importance of incorporating ecological features as a cost attribute in the transportation evaluation process. By merging an ecosystem valuation technique, such as value transfer or replacement cost to the existing spatial decision support system (SDSS), the exposed limitations improve. As mentioned, environmental externality as a whole has different implications from the economic costs of ecological consumption, and thus, it should be estimated in a projectoriented scale.

Work scopes of this study are founded on the previous Texas Urban Triangle (TUT) research results. The TUT, one of the megaregions in the USA, covers the three largest cities in the State of Texas: Houston, Dallas-Fort Worth, and San Antonio. As of 2010, it has over 18 million inhabitants within an area of more than $150,000 \mathrm{~km}^{2}$ (U.S. Census Bureau 2010). Accordingly, freight and passenger mobility within and among the Triangle's metro areas as well as outward across the continent is critical to economic and social development and to the preservation of the area's natural assets. There is an urgent need for policy and investment decisions based on a wider set of criteria accounting for new conditions and considerations.

By implementing a raster-based GIS, the studies on the TUT have optimized a high-speed rail (HSR) route with the different types of variables. The author organizes another attempt to elaborate route alternatives. The main purpose is to identify the possibility of calculating ecological impact as an opportunity cost to estimate total costs of each alternative and to test the feasibility of the routes designed with different variables. If ecological impact can be accounted for as economic costs are, would it be safe to say a route with the shortest physical (Euclidian) distance is the most economically viable option? If the difference in construction and operation costs, the two most commonly used cost elements in conventional feasibility studies, is compensated by ecological benefits, is it reasonable to choose a route that is environmentally beneficial, albeit slightly more circuitous than the shortest route? The below hypotheses are the main arguments of this study.

H1 If environmental impact can be accounted for as an economic cost, the routes optimized with environmental variables will cost less in terms of total cost than the routes designed with only socioeconomic variables.

H2 The difference in construction and operation costs can be fully compensated by the preserved economic benefits of ecological features. 
Fig. 1 Variables and factor structure

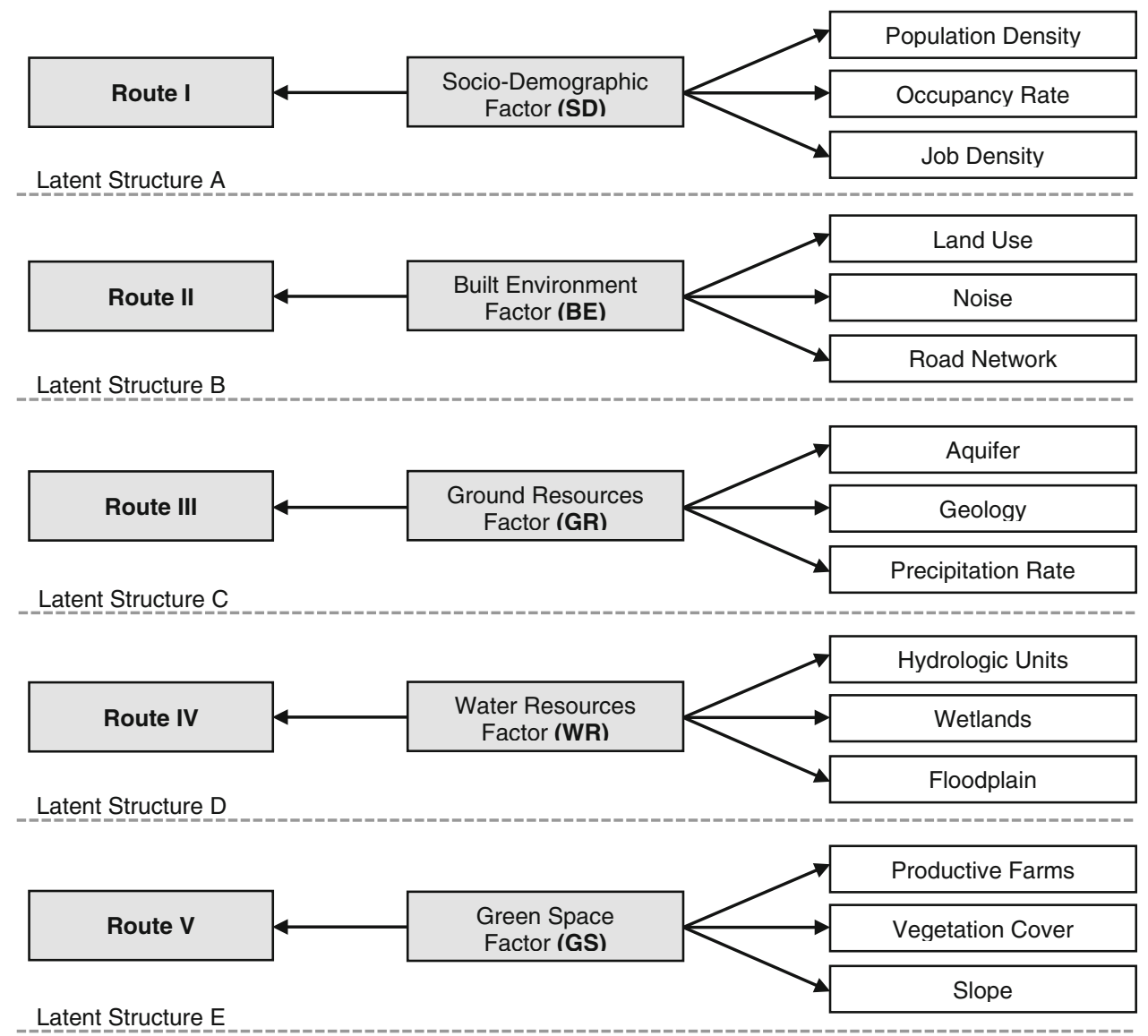

\section{Materials and methods}

Spatial decision support systems (SDSS) and HSR alternatives

In previous studies of the TUT, a statistical analysis was implemented to give more robust options in route modeling, resulting in five HSR routes between Austin and San Antonio (Kim et al. 2011, 2013, 2014). Each alternative is optimized with different variables implying different costs and impacts on the society. Compounding a factor analysis and a scenario-planning technique with raster-based GIS modeling, researchers were able to draw five HSR options. This comprehensive modeling process is known as spatial decision support systems (SDSS). Figure 1 explains the variables and their grouping structure with the confirmatory factor analysis.

The first route is optimized for socio-demographic variables, such as population density, occupancy rate, and job density, and the second option is designed in consideration of built environment variables, such as land use, noise, and road network. These two routes are more closely related to the man-made environment since the variables mainly address socio-physical settings. The third HSR option is designed around ground resource variables, such as aquifer, geology, and precipitation rate, and the fourth is characterized by hydrologic units, wetlands, and floodplain, all water resources. Finally, the fifth alternative is optimized for variables in green space, such as productive farms, vegetation covers, and vertical slope. The last three HSR alternatives are optimized using environmental variables, meaning that these routes can be considered environmentally weighted HSR route options.

Using the cost surface and the shortest path analysis, route alternatives for each latent structure are extracted. Raster-based GIS modeling is helpful as the combined functions provide a series of connected pixels based on each preferred scenario. After setting up the origin and destination points, the shortest path analysis seeks out the least possible scores around each proceeding pixel, constantly identifying what becomes a connected path to the final destination. Figure 2 illustrates each of the five alternatives, and Table 1 shows their length information.

If the hypotheses stated in the previous section stand to be valid, the last three routes' total costs should show lower estimates than the first two alternatives'. In other words, the total costs of the routes designed in accordance with the man-made variables (Paths 1 and 2) should cost more than 
Fig. 2 Five HSR alternatives between the Austin and Houston airports

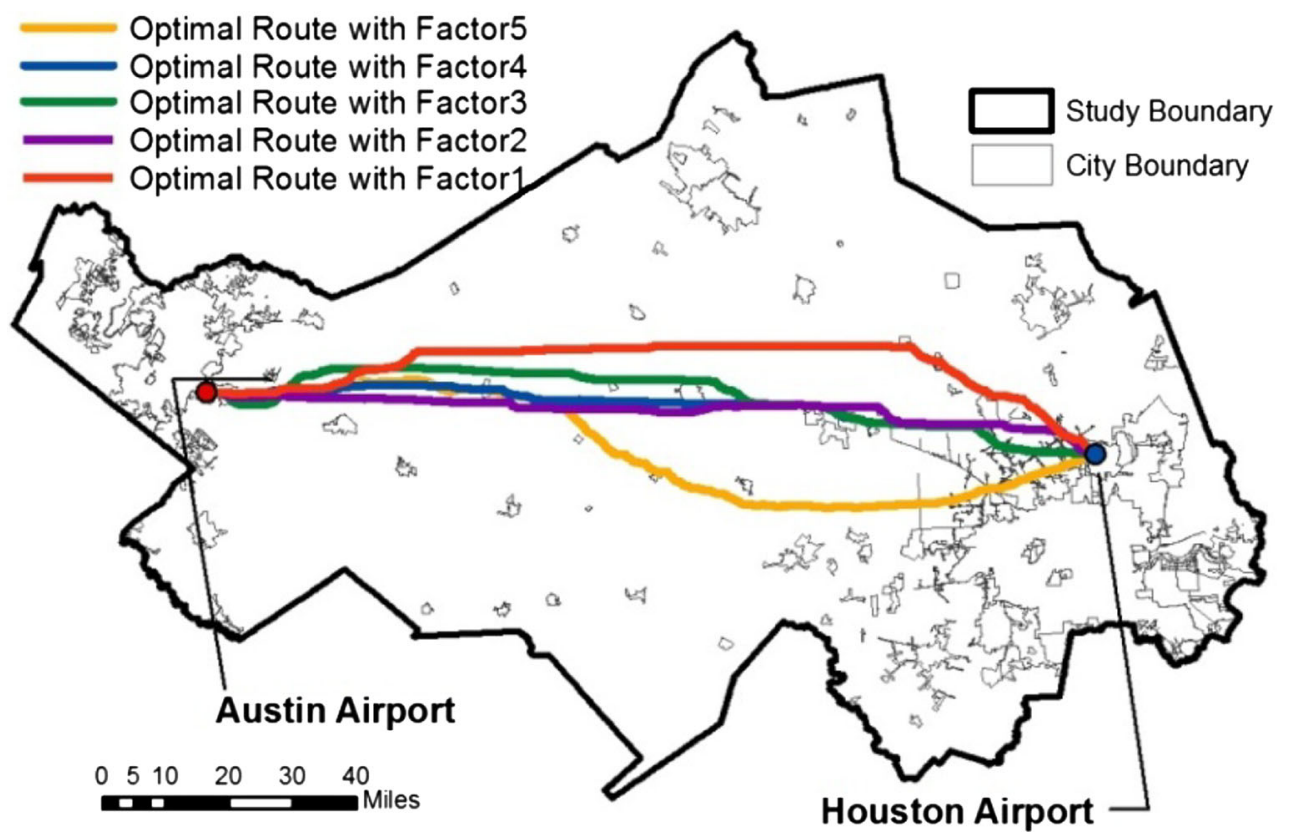

Table 1 Length information

\begin{tabular}{lllll}
\hline Path 1 & Path 2 & Path 3 & Path 4 & Path 5 \\
\hline $241.5 \mathrm{~km}$ & $233.6 \mathrm{~km}$ & $239.2 \mathrm{~km}$ & $233.6 \mathrm{~km}$ & $249.3 \mathrm{~km}$ \\
\hline
\end{tabular}

the routes optimized with environmental variables (Paths 3, 4 , and 5). Referring to the second hypothesis, the total costs of routes 1 and 2 should cost more than the optimal routes 3,4 , and 5, because the preserved economic benefits of ecological features will compensate for the cost differences. To test these statements, the author calculated and compared each route using three cost elements: construction, operation, and ecological.

Three cost elements

The most dominant method implemented in conventional feasibility studies is benefit-cost analysis (BCA). The problem of BCA arises when measuring benefits because of its subjective nature. It is hard to quantify the benefits precisely, especially for a project like HSR with which the USA has no prior experience. Also, in a transportation project, benefit depends heavily on user capacity, and user demand is one of the most difficult predictions to make (Decorla-Souza et al. 1997; De Jong 2000). Hence, instead of using uncertain features, total costs analysis includes all possible monetary interactions as costs (Chester and Horvath 2010). If any predictable financial benefit is involved, it will be accounted for as minus costs.

This study incorporates three cost elements: construction, operation, and ecological costs. Construction cost can be broken into three categories: hardware, software, and land acquisition. Operation cost is closely aligned with maintenance cost and is calculated by three attributes: variable, fixed, and value of time measures. Both of these cost elements are estimated using the Korean HSR specifications. The sponsor of the previous TUT research provided detailed cost information for construction and operation aspects of the Korean HSR. Table 2 summarizes the construction cost of each route. As most of the elements in construction cost are based on total length, Path 5 requires the priciest investment at the time of construction and Path 2 demands the least. The difference between the two is almost $\$ 752$ million. Hardware concerns the actual construction process, such as ground conditions, earthworks, and bridge constructions, whereas software refers to operating systems and labor charges. Land acquisition costs are estimated using parcel datasets acquired from the county appraisal offices.

Table 3 explains annual operating costs, which consist of variable, fixed, and value of time measurements. Variable costs change with the activity levels and are directly dependent upon the volume of ridership. On the other hand, fixed costs are predetermined and should remain stable across the route alternatives. Examples of the variable costs are track maintenance costs, communication and signal costs, vehicle costs, and energy costs. Fixed costs refer to employment and administration costs, all of which relate to human resources. Social cost is another key dimension of operational investment. In many cases, studies calculating social costs compare different transportation options such as airplane versus rail, or highway versus airplane (Janic 2003; Lu and Morrell 2006; Belhaj and Fridell 2010; Wang 
Table 2 Construction costs estimate

\begin{tabular}{|c|c|c|c|c|c|}
\hline (In million \$) & Path 1 & Path 2 & Path 3 & Path 4 & Path 5 \\
\hline Total length & $241.5 \mathrm{~km}$ & $233.6 \mathrm{~km}$ & $239.2 \mathrm{~km}$ & $233.6 \mathrm{~km}$ & $249.3 \mathrm{~km}$ \\
\hline Hardware & $\$ 5,063.66$ & $\$ 4,880.48$ & $\$ 4,954.13$ & $\$ 4,880.99$ & $\$ 5,338.79$ \\
\hline Software & $\$ 1,374.74$ & $\$ 1,329.76$ & $\$ 1,361.65$ & $\$ 1,329.76$ & $\$ 1,419.14$ \\
\hline Land acquisition & $\$ 37.17$ & $\$ 37.75$ & $\$ 36.75$ & $\$ 40.76$ & $\$ 241.52$ \\
\hline Total & $\$ 6,475.57$ & $\$ 6,247.99$ & $\$ 6,352.53$ & $\$ 6,251.53$ & $\$ 6,999.45$ \\
\hline Difference & $+\$ 227.57$ & - & $+\$ 104.53$ & $+\$ 3.53$ & $+\$ 751.46$ \\
\hline
\end{tabular}

Table 3 Operation costs estimate

\begin{tabular}{|c|c|c|c|c|c|}
\hline & Path 1 & Path 2 & Path 3 & Path 4 & Path 5 \\
\hline \multicolumn{6}{|l|}{ Costs (1) } \\
\hline Variable & $\$ 265.7 \mathrm{M}$ & $\$ 257.0 \mathrm{M}$ & $\$ 263.2 \mathrm{M}$ & $\$ 257.0 \mathrm{M}$ & $\$ 274.3 \mathrm{M}$ \\
\hline Fixed & $\$ 148.6 \mathrm{M}$ & $\$ 148.6 \mathrm{M}$ & $\$ 148.6 \mathrm{M}$ & $\$ 148.6 \mathrm{M}$ & $\$ 148.6 \mathrm{M}$ \\
\hline Total & $\$ 414.3 \mathrm{M}$ & $\$ 405.6 \mathrm{M}$ & $\$ 411.8 \mathrm{M}$ & $\$ 405.6 \mathrm{M}$ & $\$ 422.9 \mathrm{M}$ \\
\hline \multicolumn{6}{|l|}{ Value of time (2) } \\
\hline Average capacity & $\$ 4,669.55 / 1$ way trip & $\$ 4,516.80 / 1$ way trip & $\$ 4,625.08 / 1$ way trip & $\$ 4,516.80 / 1$ way trip & $\$ 4,820.37 / 1$ way trip \\
\hline Annual & $\$ 17.04 \mathrm{M}$ & $\$ 16.49 \mathrm{M}$ & $\$ 16.88 \mathrm{M}$ & $\$ 16.49 \mathrm{M}$ & $\$ 17.59 \mathrm{M}$ \\
\hline \multicolumn{6}{|l|}{ Total (1) + (2) } \\
\hline Total & $\$ 431.34 \mathrm{M}$ & $\$ 422.09 \mathrm{M}$ & $\$ 428.68 \mathrm{M}$ & $\$ 422.09 \mathrm{M}$ & $\$ 440.49 \mathrm{M}$ \\
\hline Difference & $+\$ 9.25 \mathrm{M}$ & - & $+\$ 6.59 \mathrm{M}$ & - & $+\$ 18.40 \mathrm{M}$ \\
\hline
\end{tabular}

and Sanders 2011). This study, however, compares the social costs of route options within the same means of transportation; thus, typical social costs, such as congestion or accidents, do not have significant influence on the final decision. The only possible social cost associated with HSR operation that varies by route would be the value of time, which is measured in different degrees of ridership levels.

Different measurements are used internationally in assessing the value of time. The USA applies the annual wage rate with working types (Hayashi and Morisugi 2000; Lee 2000; Morisugi 2000; Sinha and Labi 2007). According to the Bureau of Labour Statistics, the average hourly wage rate of the USA in 2011 was $\$ 23.58$ (United States Department of Labor 2012). The Korean HSR carries up to 410 passengers in one-way operation (maintenance data from the sponsor for the year 2011). And based on historic patterns, the range of ridership varies from the minimum of $10 \%$ to the average of $60 \%$ (Seo 2000). Similar measurements are found in German HSR. Studies found that the minimum occupancy of the German HSR in 2009 was $10 \%$, and the average was $63 \%$ (Chester and Horvath 2010).

Implementing the average wage rate and the ridership level, Table 3 describes annual maintenance costs with all three operational elements combined. Paths 2 and 4 show identical results, because almost all of elements in the operation costs are based on rail length. As the total length of Paths 2 and 4 is the same, their operation costs are expected to be identical. On the other hand, Path 5 shows the highest cost for its operation. The difference between Paths 5 and 4 (or 2) is about $\$ 18$ million annually. Although \$18 million may not sound a considerable amount for a project of this size, after 20-50 years of operation, the accumulated cost difference becomes rather significant.

Lastly, ecological cost is estimated using an approach known as value transfer. Value transfer is one particular methodology in the discipline of ecosystem valuation. Although location-specific or micro-level valuation studies are in demand, they generally require more intensive datasets and more precise measurements than studies at an aggregate level (Kreuter et al. 2001; Wilson et al. 2004). Thus, data availability often becomes an issue. To overcome the limitations and keep the focus on project-specific value measurements, researchers in the ecosystem science suggest a secondary analysis: value transfer (Kreuter et al. 2001; Herrera Environmental Consultants Inc., Northern Economics Inc. et al. 2004; Wilson et al. 2004; Troy and Wilson 2006). This transfer method involves obtaining an estimate for the economic value of non-market goods or services through the analysis of a single study or group of studies that have been previously carried out to value similar goods or services (Costanza and Daly 1992; 
Table 4 Value transfer studies summary

\begin{tabular}{|c|c|c|c|c|c|c|c|c|}
\hline \multirow[t]{2}{*}{ Land cover } & \multicolumn{7}{|c|}{ Economic values } & \multirow[t]{2}{*}{ Total } \\
\hline & $\begin{array}{l}\text { Overall } \\
\text { estimate }\end{array}$ & $\begin{array}{l}\text { Climate } \\
\text { regulation }\end{array}$ & $\begin{array}{l}\text { Water supply } \\
\text { and regulation }\end{array}$ & $\begin{array}{l}\text { Recreation } \\
\text { and aesthetic }\end{array}$ & $\begin{array}{l}\text { Habitat } \\
\text { refuge }\end{array}$ & Pollination & $\begin{array}{l}\text { Soil formation } \\
\text { and control }\end{array}$ & \\
\hline Open water & 2 & - & 2 & 2 & 1 & - & - & 7 \\
\hline Urban open space & 1 & 4 & 2 & 2 & - & - & - & 9 \\
\hline Forest & 3 & 6 & 3 & 4 & 9 & 2 & - & 27 \\
\hline Shrub & - & 2 & - & 9 & 4 & - & - & 15 \\
\hline Herbaceous & 1 & 2 & 3 & 1 & 1 & 1 & 2 & 11 \\
\hline Pasture & 2 & - & - & 1 & - & - & 1 & 4 \\
\hline Crop & 3 & 3 & 1 & 3 & 1 & - & 1 & 12 \\
\hline Wetland & 3 & 1 & 10 & 8 & 5 & - & - & 27 \\
\hline River/Lake & - & - & 6 & 11 & 2 & - & - & 19 \\
\hline Total & 15 & 18 & 27 & 41 & 23 & 3 & 4 & 131 \\
\hline
\end{tabular}

Table 5 Ecological cost for each route (\$/year)

\begin{tabular}{|c|c|c|c|c|c|}
\hline Land cover types (unit cost) & Path 1 & Path 2 & Path 3 & Path 4 & Path 5 \\
\hline Open water $(\$ 876.72)$ & $\$ 71,945$ & $\$ 60,442$ & $\$ 28,661$ & $\$ 35,680$ & $\$ 113,475$ \\
\hline Urban open $(\$ 1,000)$ & $\$ 772,146$ & $\$ 546,640$ & $\$ 816,402$ & $\$ 1,144,875$ & $\$ 1,140,205$ \\
\hline Forest $(\$ 245.84)$ & $\$ 427,701.85$ & $\$ 379,590.18$ & $\$ 353,402.12$ & $\$ 265,817.00$ & $\$ 193,540.15$ \\
\hline Shrub $(\$ 13.55)$ & $\$ 13,515$ & $\$ 11,159$ & $\$ 11,201$ & $\$ 10,354$ & $\$ 11,809$ \\
\hline Herbaceous (\$15.84) & $\$ 9,236$ & $\$ 7,320$ & $\$ 7,080$ & $\$ 6,968$ & $\$ 4,808$ \\
\hline Pasture (\$906.34) & $\$ 3,070,983$ & $\$ 3,601,693$ & $\$ 3,250,372$ & $\$ 3,385,418$ & $\$ 2,508,628$ \\
\hline Crop $(\$ 22.40)$ & $\$ 8,474$ & $\$ 7,193$ & $\$ 6,586$ & $\$ 6,879$ & $\$ 4,115$ \\
\hline Wetland $(\$ 1,437.89)$ & $\$ 750,506$ & $\$ 678,871$ & $\$ 444,803$ & $\$ 175,875$ & $\$ 522,188$ \\
\hline River/Lake (\$178.71) & $\$ 9,829$ & $\$ 10,723$ & $\$ 5,540$ & $\$ 4,289$ & $\$ 7,506$ \\
\hline Total & $\$ 5,134,335$ & $\$ 5,303,630$ & $\$ 4,924,047$ & $\$ 5,036,155$ & $\$ 4,506,274$ \\
\hline Differences & $+\$ 628,061$ & $+\$ 797,356$ & $+\$ 417,773$ & $+\$ 799,881$ & - \\
\hline
\end{tabular}

Costanza et al. 1997; Costanza 2000; Belhaj and Fridell 2010). When conducting a primary research work where accurate data collection is not feasible, value transfer represents a meaningful "second-best" strategy and starting point for the evaluation of environmental features (Costanza et al. 1997; Woodward and Wui 2001; Groot et al. 2002; Herrera Environmental Consultants Inc., Northern Economics Inc. et al. 2004; Wilson et al. 2004).

Estimating ecological cost using value transfer involves four steps. First, land cover types within the study area are identified, and there are nine types in this project. After that, relevant literature works are collected and summarized as transferrable values. For this study, 131 cases and 51 relevant articles have been examined. Table 4 summarizes the nine land cover types in the study area and their corresponding monetizable elements.

For the third step, transferrable ecological values are set to maximum, minimum, median, and average values. The consumer price index (CPI) is used to set each value to the same dollar year. Finally, the environmental consumption in terms of acreage is calculated for each alternative and multiplied to the adjusted ecological values. Using GIS land cover dataset, it is possible to pinpoint how much natural land covers are converted to impervious surfaces (rail tracks). Table 5 summarizes the result using the median ecological values. The reason for applying the median value is to minimize the effect of significant outliers. Because each land cover's economic value varies widely, other monetary estimates may bias the final outcome. For example, the minimum economic value of one acre of wetland is $\$ 0.4$ per year, but the maximum values could reach as high as $\$ 145,000 /$ acre/year.

Unlike with the construction and operation costs, these results show that Path 5 is the least costly alternative when ecological features are considered. On the other hand, Paths 2 and 4, which were indicated as the most feasible options in terms of operation costs, became the priciest. The difference between Paths 5 and 2 is almost $\$ 800,000 /$ year. By constructing Path 2, we would expect to lose about $\$ 5.3$ million worth of annual ecological benefits. On 
the contrary, building Path 5 would induce about $\$ 4.51$ million in annual environmental losses accounting for about $20 \%$ of the loss incurred by Path 2 . In other words, constructing Path 2 would destroy $\$ 0.8$ million of ecological features annually than doing the same with Path 5. Path 1 requires an annual ecological cost of $\$ 5.1$ million, and Paths 3 and 4 cost $\$ 4.9$ million/year and $\$ 5.04$ million/ year, respectively.

\section{Results and discussion}

Total costs with project efficiency period

Based on the three cost estimates, total costs for each route are calculated. As can be seen in Table 6, Path 2, designed with the built environment variables, is the most efficient HSR option with the given parameters. On the other hand, Path 5, optimized for green space variables, shows the priciest investment among the five alternatives. The difference between the two is almost $\$ 770$ million. The main reason can be traced to its total length difference. Most operation and some construction cost elements are based on total length, and Path 5 is the longest alternative. The difference in construction cost between Paths 2 and 5 is about $\$ 770$ million. Compared to Path 2, Path 5 requires approximately $\$ 751.5$ million more in construction and $\$ 18.4$ million more in operation. Of the total difference of $\$ 770$ million, nearly $97 \%$ is due to the large gap in construction costs.

Using the median values, the ecological cost consists of about $0.08 \%$ of the total cost. Since construction cost is essentially a one-time investment, whereas the other two are recurring costs, total costs in terms of project efficiency may change over time. Therefore, the summation of total costs over a 20-50-year time frame, a frequently used return-on-investment (ROI) period (Hayashi and Morisugi 2000; Lee 2000; Morisugi 2000), demands a separate calculation. If the ecological costs of Paths 3, 4, and 5 are less than Paths 1 and 2 within the same timeframe, total costs for the three routes can become more feasible options.

In the past literature, the lost services of ecosystem features have been defined in two ways: (1) ecosystem with permanent injury, and (2) ecosystem with natural recovery (Herrera Environmental Consultants Inc., Northern Economics Inc. et al. 2004; Wilson et al. 2004; Wilson and Hoehn 2006). The former concerns the service lost due to human interference that will never be restored, making the damages permanent. The latter describes those features also damaged by human activities, but which can recover with natural elasticity. In the latter case, a lost ecosystem will fully bounce back to its previous condition at some point in the future. HSR investment is closer to a permanent injury, as the rail tracks are intended to be long lasting. For example, AMTRAK was built in the late 1900s, and in many cases, the same rail tracks are still utilized today.

The total cost analysis with the efficiency period resulted in Path 5 being the most expensive route option and Path 4 the least costly alternative. As summarized in Table 7, implementing Path 4 requires $\$ 6.3$ billion for construction in addition to its annual costs of $\$ 422$ million for operation and $\$ 5$ million for ecological consumption. On the other hand, Path 5 induces $\$ 7$ billion of investment for its construction as well as the annual costs of $\$ 440$ million for operation. It also demands $\$ 4.5$ million in economic value of ecological features. Although the ecological cost of Path 5 is the lowest, it still is the most costly HSR route upon considering all three cost attributes. Construction cost contributes up to $43 \%$ of the total costs over 20 years, while the ecological cost only makes up about $1 \%$; thus, a 20-year timeframe cannot compensate for the construction costs incurred. The difference between Paths 2 and 5 in terms of construction cost is around $\$ 752$ million, and even for a 50-year time span, the difference between the two for their ecological costs only accounts for $\$ 40$ million. Therefore, it would take about 940 years for Path 5 to fully compensate for the costs accrued during the initial construction with the possible ecological savings.

The total cost of Path 4 came out as the most efficient and Path 5 as the priciest option for an HSR route linking Austin and Houston. As briefly mentioned, the main reason can be traced to the significant differences in construction and operation costs. In Tables 2 and 3, the differences between Paths 4 and 5 are about $\$ 748$ million in construction cost and about $\$ 17$ million/year in operation cost.

Table 6 Expected total costs of each alternative (million \$/year)

\begin{tabular}{llllll}
\hline Cost elements & Path 1 & Path 2 & Path 3 & Path 4 & Path 5 \\
\hline Construction costs & $\$ 6,475.6 \mathrm{M}$ & $\$ 6,247.9 \mathrm{M}$ & $\$ 6,352.5 \mathrm{M}$ & $\$ 6,251.5 \mathrm{M}$ & $\$ 6,999.5 \mathrm{M}$ \\
Operation costs & $\$ 431.3 \mathrm{M}$ & $\$ 422.1 \mathrm{M}$ & $\$ 428.6 \mathrm{M}$ & $\$ 422.1 \mathrm{M}$ & $\$ 440.5 \mathrm{M}$ \\
Ecological costs & $\$ 5.1 \mathrm{M}$ & $\$ 5.3 \mathrm{M}$ & $\$ 4.9 \mathrm{M}$ & $\$ 5.1 \mathrm{M}$ & $\$ 4.5 \mathrm{M}$ \\
Total costs & $\$ 6,912 \mathrm{M}$ & $\$ 6,675 \mathrm{M}$ & $\$ 6,786 \mathrm{M}$ & $\$ 6,679 \mathrm{M}$ & $\$ 7,444 \mathrm{M}$ \\
Difference & $+\$ 236.7 \mathrm{M}$ & - & $+\$ 110.7 \mathrm{M}$ & $+\$ 3.3 \mathrm{M}$ & $+\$ 769 \mathrm{M}$ \\
\hline
\end{tabular}


Table 7 Total costs with different operating periods

\begin{tabular}{|c|c|c|c|c|c|}
\hline Cost elements & Path 1 & Path 2 & Path 3 & Path 4 & Path 5 \\
\hline Construction cost & $\$ 6,475.57 \mathrm{M}$ & $\$ 6,248.00 \mathrm{M}$ & $\$ 6,352.53 \mathrm{M}$ & $\$ 6,251.53 \mathrm{M}$ & $\$ 6,999.45 \mathrm{M}$ \\
\hline \multicolumn{6}{|l|}{ Operation cost } \\
\hline Year 1 & $\$ 431.33 \mathrm{M}$ & $\$ 422.08 \mathrm{M}$ & $\$ 428.63 \mathrm{M}$ & $\$ 422.08 \mathrm{M}$ & $\$ 440.46 \mathrm{M}$ \\
\hline At year 20 & $\$ 8,626.51 \mathrm{M}$ & $\$ 8,441.53 \mathrm{M}$ & $\$ 8,572.66 \mathrm{M}$ & $\$ 8,441.53 \mathrm{M}$ & $\$ 8,809.16 \mathrm{M}$ \\
\hline At year 30 & $\$ 12,939.77 \mathrm{M}$ & $\$ 12,662.30 \mathrm{M}$ & $\$ 12,858.99 \mathrm{M}$ & $\$ 12,662.30 \mathrm{M}$ & $\$ 13,213.73 \mathrm{M}$ \\
\hline At year 40 & $\$ 17,253.03 \mathrm{M}$ & $\$ 16,883.06 \mathrm{M}$ & $\$ 17,145.32 \mathrm{M}$ & $\$ 16,883.06 \mathrm{M}$ & $\$ 17,618.31 \mathrm{M}$ \\
\hline At year 50 & $\$ 21,566.28 \mathrm{M}$ & $\$ 21,103.83 \mathrm{M}$ & $\$ 21,431.65 \mathrm{M}$ & $\$ 21,103.83 \mathrm{M}$ & $\$ 22,022.89 \mathrm{M}$ \\
\hline \multicolumn{6}{|l|}{ Ecological cost } \\
\hline Year 1 & $\$ 5.13 \mathrm{M}$ & $\$ 5.30 \mathrm{M}$ & $\$ 4.92 \mathrm{M}$ & $\$ 5.04 \mathrm{M}$ & $\$ 4.51 \mathrm{M}$ \\
\hline At year 20 & $\$ 102.69 \mathrm{M}$ & $\$ 106.07 \mathrm{M}$ & $\$ 98.48 \mathrm{M}$ & $\$ 100.72 \mathrm{M}$ & $\$ 90.13 \mathrm{M}$ \\
\hline At year 30 & $\$ 154.03 \mathrm{M}$ & $\$ 159.11 \mathrm{M}$ & $\$ 147.72 \mathrm{M}$ & $\$ 151.08 \mathrm{M}$ & $\$ 135.19 \mathrm{M}$ \\
\hline At year 40 & $\$ 205.37 \mathrm{M}$ & $\$ 212.15 \mathrm{M}$ & $\$ 196.96 \mathrm{M}$ & $\$ 201.45 \mathrm{M}$ & $\$ 180.25 \mathrm{M}$ \\
\hline At year 50 & $\$ 256.72 \mathrm{M}$ & $\$ 265.18 \mathrm{M}$ & $\$ 246.20 \mathrm{M}$ & $\$ 251.81 \mathrm{M}$ & $\$ 225.31 \mathrm{M}$ \\
\hline \multicolumn{6}{|l|}{ Total } \\
\hline In 20 years & $\$ 15,204.77 \mathrm{M}$ & $\$ 14,795.60 \mathrm{M}$ & $\$ 15,023.67 \mathrm{M}$ & $\$ 14,793.78 \mathrm{M}$ & $\$ 15,898.73 \mathrm{M}$ \\
\hline In 50 years & $\$ 28,298.57 \mathrm{M}$ & $\$ 27,617.01 \mathrm{M}$ & $\$ 28,030.38 \mathrm{M}$ & $\$ 27,607.16 \mathrm{M}$ & $\$ 29,247.66 \mathrm{M}$ \\
\hline
\end{tabular}

On the other hand, the difference in the ecological cost, the only category where Path 5 costs less than Path 4, indicates that Path 5 will cost about $\$ 0.53$ million/year less than Path 4. Therefore, Path 5 cannot compensate for the economic burden of its construction cost even when the ecological cost is summed over a 50-year timeframe (\$0.53 million $\times 50$ years $=\$ 26.5$ million). It only compensates for about $4 \%$ of the loss in construction costs $(\$ 26.5 / \$ 748$ million $=0.036)$. In order for the preserved ecological benefits of Path 5 to fully pay back the difference in construction costs, it would take about 1,400 years. Considering these figures, it would be plausible to say that the difference in construction costs is the biggest element driving the total cost of each alternative.

However, it is not possible to absolutely reject the main research hypotheses given that the total costs of Path 4 are less than those of Path 2. These two routes' lengths are the same $(233.6 \mathrm{~km})$, meaning that their length-based costs are identical. As can be seen in Table 7, total operation costs for Paths 2 and 4 are indistinguishable. This is because the calculation of operation costs largely depends on the route's total length. Therefore, the only possible differences between the two options are a few categories within construction costs (some of which are based on geologic and hydrologic units) and the elements in ecological costs.

As can be seen in Table 2, Path 4 requires about $\$ 3.53$ million more than Path 2 for its construction. Path 4 costs approximately $\$ 3$ million more in land compensation because it passes through higher value parcels than Path 2. In addition, Path 4 costs about $\$ 17.6$ million more than Path 2 in overpass bridge construction. This is because Path
2 is designed to avoid the built environment variables, such as roads and land use, and the road network is the main reason for building overpass bridges. On the other hand, Path 4 requires about $\$ 14.5$ million less in normal bridge construction. This is an expected result since Path 4 is designed to minimize the impact on water resource variables, such as hydrologic units, floodplain, and wetlands. Therefore, concerning the possibility of constructing a normal bridge, this route provides the least impact. Finally, difference in civil work costs contributes about \$2.6 million as well.

When ecological values are considered, however, Path 4 destroys fewer environmental systems than does Path 2. Using the median values, Path 4 consumes about $\$ 0.27$ million less than Path 2 (\$5.3 vs. \$5.04 million annually). Constructing Path 4 requires $\$ 3.53$ million more at the beginning of construction. But by the 14th year of operation, the induced loss in construction costs would be fully compensated for by the preserved benefits in ecological features $\quad(\$ 0.27$ million $\times 14$ years $=\$ 3.74 \quad$ million $>\$ 3.53$ million). This is an interesting result because it partially supports the second research hypothesis.

Figure 3 illustrates the result. In the 14th year of operation, the total costs of Path 2 surpass the total costs of Path 4. As can be seen in Table 5, except for Urban Open Spaces, each of the other environmental categories for Path 4 costs significantly less than the same categories for Path 2. For Urban Open Space, Path 4 is about \$0.6 million/year more expensive than Path 2. However, this loss is easily made up by the gains in the other features, such as wetland or forest services. 


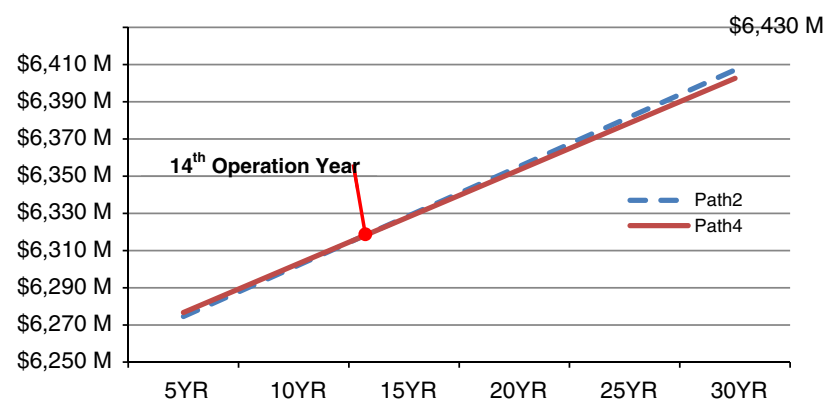

Fig. 3 Cost shift in a 30-year timeframe

\section{Conclusion}

Constructing Path 4 for the Austin-to-Houston segment would be the most suitable HSR route with the given criteria. Compared to Path 1, it will save about \$224 million in construction, about $\$ 9.3$ million in its annual operation expenses, and about $\$ 0.1$ million in annual ecological values. Furthermore, compared to Path 5, Path 4 saves about $\$ 747.9$ million in construction, and about $\$ 18.4$ million in its annual operation costs. However, it would cost about $\$ 0.53$ million more in annual economic values of ecological features. Finally, compared to Path 2, the most similar option in terms of total costs, Path 4 will require about $\$ 3.53$ million more in its construction. Nonetheless, in the 14th operation year, this loss will be compensated for by the economic value of preserved ecological resources, such as wetlands, pasture, and forest.

Total cost analysis is intended to merge specific ecological consumptions in the project evaluation process. As discussed previously, project evaluation in the USA often leaves out ecological costs from consideration, while hinging on construction and operation costs when selecting a transportation project. In addition, the traditional environmental impact analysis, a substitute frequently applied to measure the impact on environmental features, is conducted with a scoring system and in an aggregated level analysis. Therefore, the specific degree of impact on the natural asset is hard to accurately pinpoint. To resolve these issues, detailed ecological features are identified using land cover datasets and are incorporated in the evaluation process.

Although the main hypotheses are not completely supported, the framework for infrastructure investment suggested in this paper is meaningful. The implementation of value transfer allowed for the estimation of environmental externalities in a more detailed way, and it enabled route interpretation and comparison in a more unified, systematic manner. According to the analysis, if the differences in fixed costs are not overly significant, the economic benefits of the preserved ecological services could outweigh the construction and operation costs over a longer time period.
As noted by many preceding research works (Banerjee et al. 2009; Liao et al. 2013), the relationship between transport, land use, and environment become critical as their coordination drives a more sustainable built environment. In this extent, articulating the ecological impact prompted by a particular transport and its corresponding resource management provides a new perspective on the traditional transportation planning process. With the utilization of GIS and ecological valuation, this study contributes meaningfully to future studies aiming for more project-oriented perspectives in transport externalities.

Acknowledgments This study is a part of a longitudinal study about the Texas Urban Triangle. The author gratefully acknowledges POSCO Engineering, Inc., for their provision of the Korean high-speed rail specifications and other technology sharing.

\section{References}

Abbaspour M, Soltaninejad A (2004) Design of an environmental assessment model on the effect of vehicle emission in greater Tehran on air pollution with economic sensitivity. Int J Environ Sci Technol 1(1):27-38

Adamowicz W (2003) Valuation of environmental externalities. In: Hensher DA, Button KJ (eds) Handbook of transport and the environment. Elsevier Ltd., Oxford, pp 375-389

Banerjee D, Chakraborty S et al (2009) Appraisal and mapping the spatial-temporal distribution of urban road traffic noise. Int $\mathrm{J}$ Environ Sci Technol 6(2):325-335

Belhaj M, Fridell E (2010) External costs in the transport sector: a literature review. The Swedish Environmental Research Institute, Stockholm

Bockstael N, Costanza R et al (1995) Ecological economic modeling and valuation of ecosystems. Ecol Econ 14(2):143-159

Chester M, Horvath A (2010) Life-cycle assessment of high-speed rail: the case of California. Environ Res Lett 5:014003

Costanza R (2000) Social goals and the valuation of ecosystem services. Ecosystems 3(1):4-10

Costanza R, Daly HE (1992) Natural capital and sustainable development. Conserv Biol 6(1):37-46

Costanza R, d'Arge R et al (1997) The value of the world's ecosystem services and natural capital. Nature 387:253-260

De Jong WM (2000) Cost-effective use of evaluation models: an empirical cross-national investigation. Int $\mathrm{J}$ Technol Manag 19(3):368-383

Decorla-Souza P, Everett J et al (1997) Total cost analysis: an alternative to benefit-cost analysis in evaluating transportation alternatives. Transportation 24(2):107-123

Groot SR, Wilson AM et al (2002) A typology for the classification, description, and valuation of ecosystem functions, goods, and services. Ecol Econ 41:393-408

Hayashi Y, Morisugi H (2000) International comparison of background concept and methodology of transportation project appraisal. Transp Policy 7:73-88

Herrera Environmental Consultants Inc., Northern Economics Inc. et al (2004) Ecological economic evaluation, Maury Island, King County, Washington. Department of Natural Resources and Parks, Seattle

Janic M (2003) High-speed rail and air passenger transport: a comparison of the operational environmental performance. J Rail Rapid Transit 217(4):259-269 
Kim H, Wunneburger DF et al (2011) Texas Urban Triangle: pilot study to implement a spatial decision support system for sustainable mobility. Texas Transportation Institute, College Station

Kim H, Wunneburger DF et al (2013) High-speed rail route and regional mobility with a raster-based decision support system: the Texas Urban Triangle case. J Geogr Inf Syst 5(6):559-566

Kim H, Wunneburger DF et al (2014) Optimizing high-speed rail routes using a spatial decision support system (SDSS): the Texas Urban Triangle case. J Transp Geogr 34:194-201

Kreuter UP, Harris HG et al (2001) Change in ecosystem service values in the San Antonio Area, Texas. Ecol Econ 39(3):333-346

Lee DB (2000) Methods for evaluation of transportation projects in the USA. Transp Policy 7:41-50

Liao C-H, Chang C-L et al (2013) Correlation between land-use change and greenhouse gas emissions in urban areas. Int $\mathrm{J}$ Environ Sci Technol 10(6):1275-1286

Lu C, Morrell P (2006) Determination and applications of environmental costs at different sized airports: aircraft noise and engine emissions. Transportation 33:45-61

Maxwell S (1994) Valuation of rural environmental improvements using contingent valuation methodology: a case study of the Marston vale community forest project. J Environ Manag 41(4):385-399

Mishra R, Parida M et al (2010) Evaluation and analysis of traffic noise along bus rapid transit system corridor. Int J Environ Sci Technol 7(4):737-750

Morisugi H (2000) Evaluation methodologies of transportation projects in Japan. Transp Policy 7:35-40

Quinet E (2003) Evaluation of environmental impacts. In: Hensher DA, Button KJ (eds) Handbook of transport and the environment. Elsevier Ltd., Oxford, pp 357-373

Seo K (2000) Assessment of the basic plan of the Kyungbu highspeed rail. Technical Paper Unpublished
Sinha CK, Labi S (2007) Impacts on wetlands and other ecosystems. In: Transportation decision making: principles of project evaluation and programming. Wiley, Hoboken, NJ, pp 313-336

Thompson IB (1993) Anew kind of location decision: where to build high-speed railway stations: the French case. Scott Geogr Mag 109(2):106-110

Troy A, Wilson MA (2006) Mapping ecosystem services: practical challenges and opportunities in linking GIS and value transfer. Ecol Econ 60(2):435-449

Turner RK, Jones MS et al (2010) Ecosystem valuation: a sequential decision support system and quality assessment issues. Ann N Y Acad Sci 1185:79-101

U.S. Census Bureau (2010) State and County Quickfacts. http:// quickfacts.census.gov/qfd/states/48000.html. Retrieved 09 March 2011

United States Department of Labor (2012) May 2011 National occupational employment and wage estimates. http://www.bls. gov/oes/2011/may/oes_nat.htm. Retrieved 19 Nov 2012

Vossiniotis G, Assimacopoulos D (1999) The marginal environmental costs of transport in Greece. Global Nest J 1(2):77-89

Wang X, Sanders L (2011) Energy consumption and carbon footprint of high-speed rail projects: using CAHSR and FHSR as examples. J Rail Rapid Transit 0:1-10

Wilson MA, Hoehn JP (2006) Valuing environmental goods and services using benefit transfer: the state-of-the-art and science. Ecol Econ 60(2):335-342

Wilson MA, Troy A et al (2004) The economic geography of ecosystem goods and services. In: Dieterich M, Straaten J (eds) Cultural landscapes and land use: the nature conservation-society interface. Kluwer Academic, Boston, pp 69-94

Woodward RT, Wui YS (2001) The economic value of wetland services: a meta-analysis. Ecol Econ 37(2):257-270 